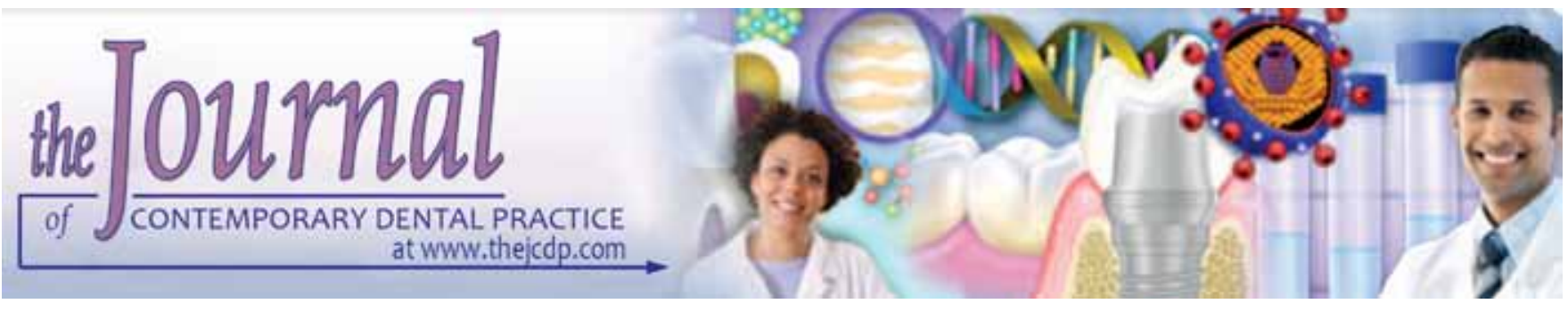

\title{
Comparison of Mutans Streptococcal Strains of Father, Mother, and Child in Indian Families using Chromosomal DNA Fingerprinting
}

\author{
Amar N Katre, SG Damle
}

\begin{abstract}
Introduction: It is now understood and accepted that there is a direct transmission of mutans streptococci (MS) from the mother to the child. There is also a direct correlation between the levels of MS in the mother and the caries status of the child. Advanced technologies in molecular biology like chromosomal DNA fingerprinting have established beyond doubt that the mother and the child bear similar strains of MS.
\end{abstract}

Aim: A study was designed with the aim of comparing the MS strains between the father, mother and the child in Indian families.

Materials and methods: A group of 20 Indian families comprising of the father, mother and child were selected and divided into caries free and caries active groups. Mixed salivary samples were collected from the individuals and were cultured for the growth of Mutans streptococci. The colonies were counted on a colony counter and a comparison was made between the mutans streptococcal counts of the mother and the caries status of the child. Further, the genotypes of the father, mother and the child were isolated and compared using the technique of chromosomal DNA fingerprinting. Following electrophoresis, the band pattern obtained was compared for similarities or differences. The results of the same were tabulated and evaluated statistically.

Results: When the colony counts of the mother (in CFU/ml) were compared with the 'dft' status of the child, a positive correlation was seen in group II. Intergroup comparison using the unpaired $\mathrm{T}$ test was statistically significant. Electrophoretic analysis of the chromosomal DNA on the agarose gels revealed identical band patterns in 13 mother-child pairs, which was statistically significant. Three of the father-child pairs showed identical band patterns, which was statistically significant. Intergroup comparison using Chi-square test was not statistically significant.

Conclusion: One may conclude that irrespective of the caries status of the child, majority of the mother child pairs share identical strains of MS and hence the mother is the primary source of infection. However, in children with a high dft, the father may also play an important role in the acquisition and transmission of MS.

Keywords: Mutans streptococci, Genotype, Chromosomal DNA fingerprinting.

How to cite this article: Katre AN, Damle SG. Comparison of Mutans Streptococcal Strains of Father, Mother, and Child in Indian Families using Chromosomal DNA Fingerprinting. J Contemp Dent Pract 2013;14(5):911-916.

Source of support: Nil

Conflict of interest: None declared

\section{INTRODUCTION}

Dental caries is a unique disease in several important respects that continues throughout ones lifetime. ${ }^{1,2}$ The disease still prevails as a worldwide epidemic and is a matter of great clinical concern till date. ${ }^{3,4}$

A group of phenotypically similar organisms collectively called as 'mutans streptococci' have been implicated as the principal bacterial component responsible for dental caries in humans. ${ }^{5,6}$ Infants do not harbor these organisms until after the teeth erupt; mutans streptococci require the presence of a hard nondesquamating surface for their colonization. ${ }^{7,8}$

Research has shown that infants acquire mutans streptococci during a discrete period between the ages of 19 to 31 months, this period is designated as 'window of infectivity" and the initial source of infection is the mother. The fidelity of transmission is defined as the commonality of genotypes between mother-infant pairs. ${ }^{10}$ A number of methods have been devised for comparison of similarity of bacterial strains between the mother and infant like as follow:

a. Bacteriocin typing ${ }^{11,12}$

b. Serotyping $^{7}$

c. Presence of plasmids ${ }^{13}$ 
However, DNA analysis based on genotypic traits offer more rapid and reliable identification of bacterial strains as compared to any of the above methods, which are based on phenotypic characterization. ${ }^{14}$

However, limited data is available on the father's role in the transmission of mutans streptococci. ${ }^{14,15}$ Also, it is not clear if the intrafamilial transmission of mutans streptococci varies in different populations and in different countries. ${ }^{14}$

Keeping these facts in mind, a study was planned and carried out with the following aims and objectives:

1. To correlate the mutans streptococcal counts in the mother, as measured in $\mathrm{CFU} / \mathrm{ml}$, with the caries status in the child.

2. To compare the strains of mutans streptococci in father, mother and child using chromosomal DNA fingerprinting.

\section{MATERIALS AND METHODS}

A total of 20 Indian families with children in the age group of 10 months -3 years were included. Care was taken to include an equal number of boys and girls. All families had a similar socioeconomic background and more or less similar dietary habits. Only those individuals were selected who were in good general health. All children selected had a $\mathrm{H} / \mathrm{o}$ complete and regular immunization. All children had a H/o weaning starting from 9 to 12 months of age. Individuals with physical limitations hindering saliva collection, medically compromised individuals and with a H/o antibiotic intake 6 months prior to the commencement of the study were excluded from the study.

All the subjects underwent a thorough dental examination and dental caries was scored as 'DMFT' for the adults and 'dft' for children using the WHO (1997) ${ }^{16}$ criteria. The families were divided into 2 groups:

Group I: Those having children with ' 0 ' dft.

Group II: Those having children with $\mathrm{dft}>4$

Two milliliter of paraffin stimulated mid morning mixed salivary samples were collected from each adult in duly labeled sterile Eppendorff tubes. For children, the samples were collected using a sterile earbud with cotton wrapped around both the ends. The ends of the bud were kept below the ventral surface of the tongue until saturated. Following this, the ends of the buds were cut away with a sterile pair of scissors and transferred immediately to duly labeled Eppendorff tubes. All tubes were immediately sealed and were ready for culturing. ${ }^{9,14}$

MSB agar was prepared by adding 0.2 units of bacitracin $/ \mathrm{ml}$ and sucrose to a concentration of $20 \%$ to mitis salivarius agar. ${ }^{17}$ The saliva samples were plated and the buds were streaked onto MSB agar plates. The plates were incubated at $37^{\circ} \mathrm{C}$ for 48 hours in a $\mathrm{CO}_{2}$ incubator $\left(5 \% \mathrm{CO}_{2}\right)$ and examined for growth of mutans streptococci. The colonies were identified by the morphology, i.e. white, rough, heaped up and detachable from the agar surface.

The colony counts of the mother in CFU/ml were counted using a colony counter. For this purpose, the agar plates with colonies were mounted onto the colony counter and fixed to the same. The colonies per grid were then counted using the attached probe.

Nine fathers in group I and 9 in group II showed MS growth. Nine mothers in group I and all mothers from group II showed MS growth. Two children from group one and one child from group II failed to show any MS growth. These families were hence excluded from the process of DNA isolation.

The process of DNA isolation, digestion, electrophoresis and gel analysis was done as per the method described by Emanuelsson et al. ${ }^{14}$ Cultures obtained previously were streaked on MSB agar plates and grown for 48 hours at $37^{\circ} \mathrm{C}$ in a $\mathrm{CO}_{2}$ incubator $\left(5 \% \mathrm{CO}_{2}\right)$ till mid logarithmic growth phase. In each culture, $0.25 \mathrm{mg}$ of glycine was added and the culture was again incubated at $37^{\circ} \mathrm{C}$ for 45 minutes under gentle agitation. Cells were then pelleted out by centrifugation and rinsed with $0.1 \mathrm{M}$ Tris-hydroxy methyl aminomethane ( $\mathrm{pH} \mathrm{8)}$ and re centrifuged. They were then suspended in $150 \mu$ lof lysis buffer $(2.5 \mathrm{ml}$ of 1 $\mathrm{M}$ Tris, $2 \mathrm{ml}$ of $0.5 \mathrm{M}$ EDTA, $0.9 \mathrm{~g}$ of glucose and water up to $100 \mathrm{ml}$ ) and sonicated for 5 seconds. To lyse the cells, $9 \mu 1$ of $5 \mathrm{M} \mathrm{NaCl}$ and $150 \mu 1$ of $10 \%$ SDS were added. After 10 minutes of incubation at room temperature, $450 \mu \mathrm{l}$ of phenyl chloroform was added and the solution was briefly vortexed and centrifuged at $16,000 \mathrm{~g}$ for 8 minutes. The supernatant was collected and mixed with $900 \mu 1$ of $95 \%$ ethanol and centrifuged again at $16,000 \mathrm{~g}$ for 15 minutes. The pellet obtained was washed twice in $200 \mu \mathrm{l}$ of $70 \%$ ethanol and centrifuged for 15 minutes. This procedure was followed for all the cultures.

The DNA pellet obtained was dissolved in $50 \mu \mathrm{l}$ of double distilled water and stored at $40^{\circ} \mathrm{C}$ in the refrigerator. $25 \mu 1$ of this DNA was pipetted out using a micropipette. To this was added $2 \mu 1$ of the enzyme restriction endonuclease Hae III. $3 \mu \mathrm{l}$ of the corresponding buffer was mixed and incubated at $37^{\circ} \mathrm{C}$ for 1 hours. After incubation, $10 \mu \mathrm{l}$ of Stopmix $(0.025 \%$ Bromophenol blue, 5\% SDS and 30\% glycerol) was added to terminate the digestive process. The same procedure was repeated for all the DNA isolates.

The gel was made by adding $0.8 \mathrm{gm}$ of Agarose to a solution of $2 \mathrm{ml} 50 \mathrm{X}$ TBE (Trisborate EDTA) $+98 \mathrm{ml}$ Distil water. This yielded a gel mixture of $0.8 \%$ agarose in 1X TBE (0.09 M Trisborate $+0.09 \mathrm{M}$ Boric acid +0.002 M EDTA), which was used for the electrophoretic analysis. The gel was digested thoroughly by boiling for 90 seconds. The molten gel was cooled to approximately $50^{\circ} \mathrm{C}$ and 
$10 \mathrm{M}$ Ethidium bromide was added. The molten gel was poured into prefabricated molds and allowed to solidify for 30 minutes before use.

The restriction fragments were separated by electrophoresis through $0.8 \%$ agarose gels for 1.5 hours at $100 \mathrm{~V}$ in Trisborate EDTA buffer. Lambda DNA Hind III digest was used as a molecular marker. Each gel had 10 wells. The molecular marker was run in the 1 st well and DNA isolates of each of the 3 family members were run in the remaining 9 wells. Thus each gel showed the band pattern of 3 families. Separate gels were used for groups I and II.

The gels were dried using a moistened cellophane paper, which was placed on either side of the gel. Care was taken to avoid entrapment of air or water bubbles between the gel and cellophane paper.

The band patterns obtained on the gels were viewed on a UV viewer and photographed with a digital camera (Figs 1 to 6). The band patterns for each of the individuals, i.e. mother, father and child were compared with the standard molecular marker for similarity in appearance. The data obtained was organized, tabulated and analyzed statistically.

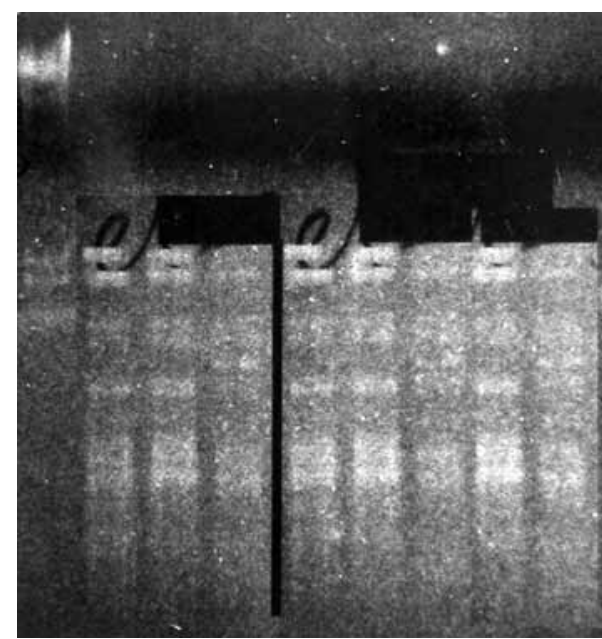

Fig. 1: Gel 1

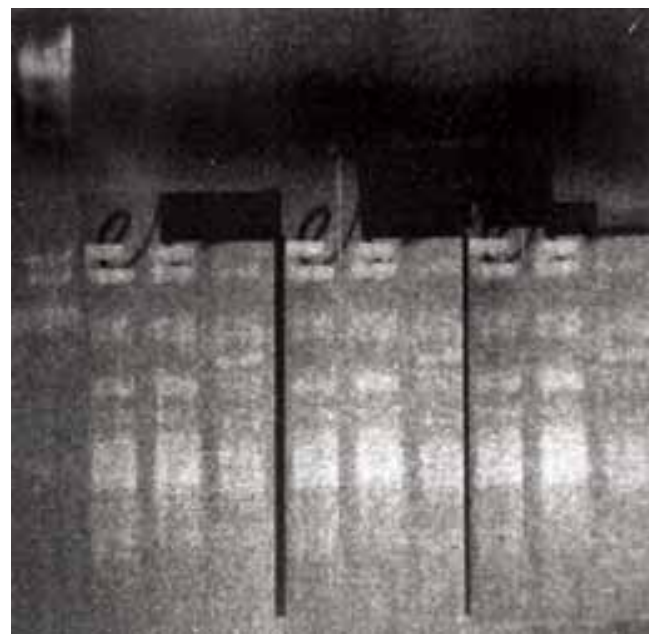

Fig. 2: Gel 2

\section{RESULTS}

The growth of mutans streptococci was seen in 18 of the 20 fathers $(90 \%), 19$ of the 20 mothers $(95 \%)$ and 17 out of the 20 children (85\%). The children from families 1, 7 and 14, both parents from family 7 and father from family 18 failed to show any growth of mutans streptococci and hence were eliminated from the statistical analysis.

When the colony counts of the mother (in CFU/ml) were compared with the 'dft' status of the child, a positive correlation was seen in group II $(\mathrm{R}=0.7405, \mathrm{p}=0.0115)$. intergroup comparison using the unpaired t-test was statistically significant $(\mathrm{t}$-value $=10.113, \mathrm{p}<0.0001)$ (Table 1)

Electrophoretic analysis of the chromosomal DNA on the agarose gels revealed identical band patterns in 13 motherchild pairs $(81.25 \%)$, which was statistically significant $(\mathrm{Z}=2.500, \mathrm{p}=0.0124)$ (Table 2$)$. Only 3 of the fatherchild pairs showed identical band patterns, which was statistically significant $(Z=2.500, p=0.0124)$ (Table 3).

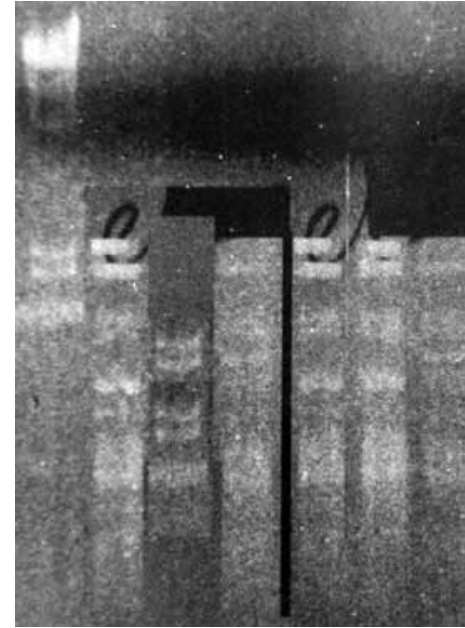

Fig. 3: Gel 3

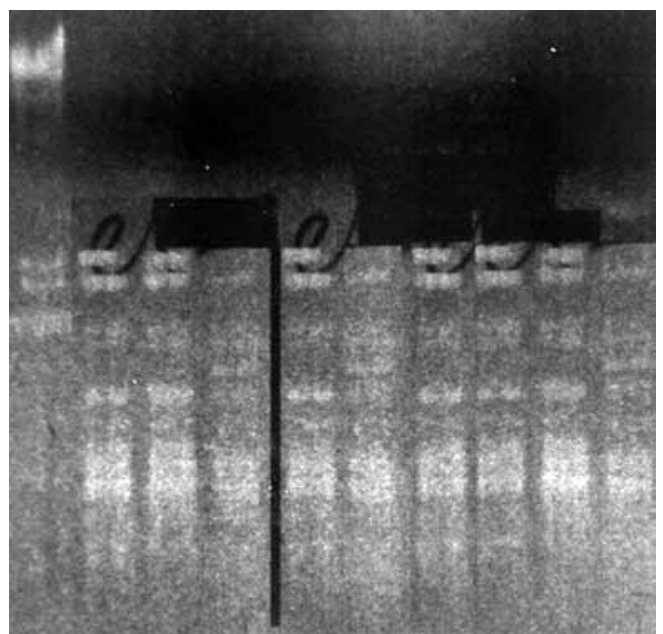

Fig. 4: Gel 4 


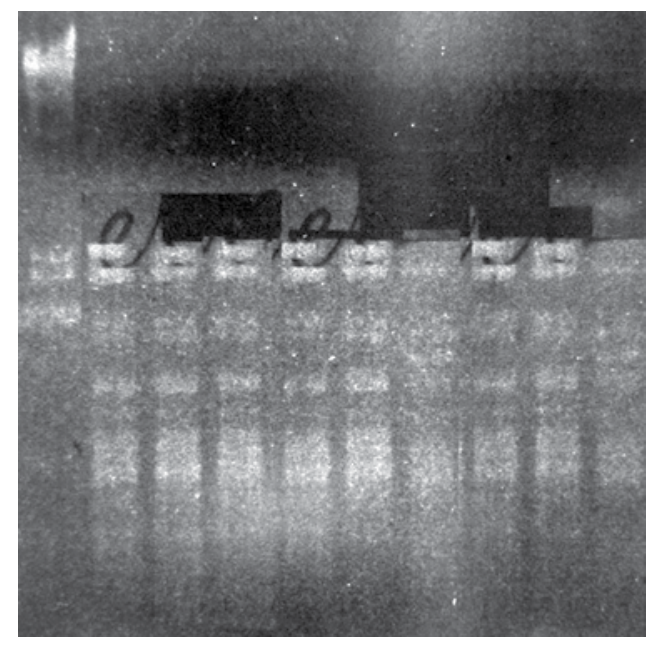

Fig. 5: Gel 5

In group I, 6 of the 8 mother-child pairs showed identical band patterns $(75 \%)$, whereas 2 mother-child pairs (families 4 and 9) showed dissimilar band patterns (25\%). In group II, 7 of the 8 mother-child pairs showed identical band patterns $(87.5 \%)$, whereas 1 mother-child pair (family 12) showed dissimilar band patterns $(12.5 \%)$. Intergroup comparison using the Chi-square test was not significant $\left(\chi^{2}=0.4103, p=0.5218\right)$ (Table 2).

In group I, none of the father-child pairs showed identical band patterns. In group II, 3 of the 8 father-child pairs showed identical band patterns $(37.5 \%)$, whereas 5 father-child pairs showed dissimilar band patterns (62.5\%). Intergroup comparison using the Chi-square test was not significant $\left(\chi^{2}=1.641, \mathrm{p}=0.2002\right)($ Table 3$)$.

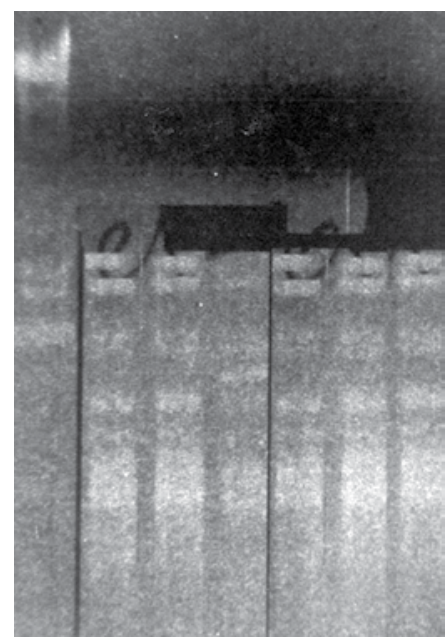

Fig. 6: Gel 6

\section{DISCUSSION}

Dental caries is a multifactorial disease that continues throughout once lifetime. ${ }^{1,2}$ It is an infectious and transmissible disease and is a matter of critical concern today. ${ }^{2}$ The 3 principal components responsible for dental caries are susceptible host, fermentable carbohydrates and most importantly cariogenic microorganisms, most notably, mutans streptococci. ${ }^{5,6}$

It is thought that the major source from whence the infants acquire MS is their mothers. Berkowitz and Jordan, ${ }^{11}$ Kohler and Bratthall, ${ }^{18}$ Rogers, ${ }^{12}$ Caufield et al,${ }^{13,19} \mathrm{Li}$ and Caufield ${ }^{10}$ have shown that mothers and children share common strains of MS. Kohler et $\mathrm{a}^{20}$ have concluded that children who acquire strains of MS at an early age are at a

\begin{tabular}{|c|c|c|c|c|c|c|c|}
\hline Sample & Count & CFU/ml & $d f t$ & Sample & Count & CFU/mI & $d f t$ \\
\hline MF 1 & 4 & $4.0 \times 10^{3}$ & 0 & MA 1 & 187 & $1.87 \times 10^{5}$ & 5 \\
\hline MF 2 & 9 & $9.0 \times 10^{3}$ & 0 & MA 2 & 110 & $1.10 \times 10^{5}$ & 4 \\
\hline MF 3 & 8 & $8.0 \times 10^{3}$ & 0 & MA 3 & 168 & $1.68 \times 10^{5}$ & 6 \\
\hline MF 4 & 6 & $6.0 \times 10^{3}$ & 0 & MA 4 & 95 & $0.95 \times 10^{5}$ & 4 \\
\hline MF 5 & 11 & $11.0 \times 10^{3}$ & 0 & MA 5 & 204 & $2.04 \times 10^{5}$ & 6 \\
\hline MF 6 & 9 & $9.0 \times 10^{3}$ & 0 & MA 6 & 134 & $1.34 \times 10^{5}$ & 4 \\
\hline MF $7^{*}$ & - & - & 0 & MA 7 & 153 & $1.53 \times 10^{5}$ & 6 \\
\hline MF 8 & 10 & $10.0 \times 10^{3}$ & 0 & MA 8 & 197 & $1.97 \times 10^{5}$ & 7 \\
\hline MF 9 & 8 & $8.0 \times 10^{3}$ & 0 & MA 9 & 89 & $0.89 \times 10^{5}$ & 5 \\
\hline MF10 & 3 & $3.0 \times 10^{3}$ & 0 & MA 10 & 142 & $1.42 \times 10^{5}$ & 6 \\
\hline Mean & 7.56 & - & & Mean & 147.90 & - & 5.30 \\
\hline SD & 2.70 & - & & SD & 41.43 & - & 1.06 \\
\hline
\end{tabular}

*- No growth of mutans streptococci

Note: Dilution factor is $10^{3}$

Correlation between count and 'dft' in child in group II

\begin{tabular}{lll}
\hline Correlation $\mathrm{R}=0.7045$ & $\mathrm{p}=0.0115$ & Significant \\
\hline Unpaired T test applied between counts in groups I and II & \\
\hline Unpaired t-test value $=10.113 \quad \mathrm{p}<0.001$ & Significant \\
\hline
\end{tabular}


Comparison of Mutans Streptococcal Strains of Father, Mother, and Child in Indian Families using Chromosomal

\begin{tabular}{ccccccccccc}
\multicolumn{10}{c}{ Table 2: Group-wise comparison of band patterns in mother-child pairs } \\
\hline Group I & Matched & $\%$ & Unmatched & $\%$ & Group II & Matched & $\%$ & Unmatched & $\%$ \\
\hline 8 & 6 & 75 & 2 & 25 & 8 & 7 & 87.5 & 1 & 12.5 \\
\hline
\end{tabular}

$Z=2.500, p=0.0124$

Chi-square applied between mother - child pairs in groups I and II

\begin{tabular}{|c|c|c|c|c|c|c|c|c|c|}
\hline$\chi^{2}=0.4103$ & & & $=0.5218$ & & ignificant & & & & \\
\hline Group I & Matched & $\%$ & Unmatched & $\%$ & Groun II & Matched & $\%$ & Unmatched & $\%$ \\
\hline 8 & 0 & 0 & 8 & 100 & 8 & 3 & 37.5 & 5 & 62.5 \\
\hline
\end{tabular}

$Z=-2.500, p=0.0124$

Chi-square applied between father - child pairs in groups I and II

$\chi^{2}=0.1641 \quad p=0.2002 \quad$ Not significant

higher risk to develop dental caries. Berkowitz et $\mathrm{al}^{21}$ and Thorild et $\mathrm{al}^{22}$ have shown a direct correlation between the levels of MS in mothers with their levels in the child.

Researchers have used serotyping (Berkowitz et al) ${ }^{7}$ Bacteriocin typing (Rogers) ${ }^{12}$ and detection of plasmids (Caufield et al) ${ }^{13,19}$ for isolation and comparison of strains between the mother and the child. However, with the advent of modern techniques in molecular biology the genotypic methods, which are more rapid and reliable ${ }^{14}$ have replaced the phenotypic methods. Li and Caufield, ${ }^{10}$ Kozai et al, ${ }^{15} \mathrm{Li}$ et $\mathrm{al}^{23}$ and Emanuelsson et $\mathrm{al}^{14,24}$ have used chromosomal DNA fingerprinting to compare the strains of the mother and the child. Saarela et $\mathrm{al}^{25}$ have also studied the transmission of MS between spouses.

However, very few studies have discussed the role of the father in the transmission of MS to the children. The data regarding the Indian population is virtually non existent. In our study, we found a direct correlation between the MS counts in the mother as measured in CFU/ml with the caries status (dft) in children in group II which was statistically significant. The DNA fingerprinting pattern revealed that $81.25 \%$ of the mothers shared common strains with the child as contrasted to only $18.75 \%$ of the fathers. This was probably due to the fact that in Indian households, the mother is the primary caretaker of the child. Also, the present study showed that only 3 of the $16(18.75 \%)$ of the father-child pairs showed an identical band pattern, all these pairs being from group II, i.e. the children with higher $\mathrm{dft}$.

\section{Clinical Significance}

The study shows that in children with higher dft, the father may play an important role in acquisition and transmission of MS. Hence, preventive strategies should include the father in addition to the mother and the child. Measures taken to reduce the colony counts of MS in fathers, including but not limited to regular professional oral prophylaxis, mouthrinses and timely intervention for management of dental caries in the form of operative, endodontic or surgical procedures may go a long way in not only maintaining the oral and dental health of the father and the mother, but also of the child, thus brightening the prospect of a caries free generation.

\section{CONCLUSION}

Thus, one may conclude that irrespective of the caries status of the child, majority of the mother child pairs share identical strains of MS and hence the mother is the primary source of infection. However, in children with a high $\mathrm{dft}$, the father may also play an important role in the acquisition and transmission of MS. But, further research using different restriction enzymes and a large sample size is required to open up new avenues in this relatively unventured field of science.

\section{REFERENCES}

1. Bowen WH. Wither or whither caries research? Caries Res 1999;33(1):1-3.

2. Caufield PW. Dental caries - a transmissible and infectious disease revisited: a position paper. J Ped Dent 1997;19(8):4-22.

3. Wefel JS, Donly KJ. Cariology. (Preface) Dent Clin North Am 1999;43(4):ix.

4. Keyes PH. Present and future methods of caries control. J Am Dent Assoc 1969;79:1395-1404.

5. Loesche WJ, et al. Association of Streptococcus mutans in human dental decay infect. Immunol 1975;11:1252-1260.

6. Loesche WJ. Role of Mutans streptococci in human dental decay. Microbiol Rev 1986;50(4):353-380.

7. Berkowitz RJ, Jordan HV, White G. The early establishment of Streptococcus mutans in the mouths of infants. Arch Oral Biol 1975;20:171-174

8. Catalanatto FA, Shklair IJ, Keene HJ. Prevalence and localization of Streptococcus mutans in infants and children. J Am Dent Assoc 1975;91:606-609.

9. Caufield PW, Cutter GR, Dasanayake AP. Initial acquisition of mutans streptococci by infants: evidence of a discrete window of infectivity. J Dent Res 1993;72(1):37-45.

10. Li Y, Caufield PW. The fidelity of initial acquisition of mutans streptococci by infants from mothers. J Dent Res 1995;74: 681-685.

11. Berkowitz RJ, Jordan HJ. Similarity of bacteriocins of Streptococcus mutans of mother and infant. Arch Oral Biol 1975; 20:725-730. 
12. Rogers AH. The source of infection in intrafamilial transfer of Streptococcus mutans. Caries Res 1981;15:26-31.

13. Caufield PW, Wannemuhler Y, Hansen JB. Familial clustering of Streptococcus mutans cryptic plasmid strain in a dental clinic population. Infect Immunol 1982;38:785-787.

14. Emanuelsson IR, Li Y, Bratthall D. Genotyping shows different strains of mutans streptococci between father and child pairs within parental pairs in Swedish families. Oral Microbiol Immunol 1998;13:271-277.

15. Kozai K, et al. Intrafamilial distribution of mutans streptococci in Japanese families and the possibility of father-child transmission. Microbiol Immunol 1999;43(2):99-106.

16. Oral Health Surveys, World Health Organization, Geneva 1999.

17. Gold OG, Jordan HV, van Houte J. A selective medium for Streptococcus mutans. Arch Oral Biol 1973;18:1357-1364.

18. Kohler B, Bratthall D. Intrafamilial levels of Streptococcus mutans and some aspects of bacterial transmission scand. J Dent Res 1978;86:35-42.

19. Caufield PW, et al. Distinct bacteriocins correlate with different group of Streptococcus mutans plasmids Infect. Immunol 1985;48:51-56.

20. Kohler B, Andreen I, Jonsson B. The earlier the colonization by mutans streptococci, the higher the caries prevalence. Oral Microbiol Immunol 1988;3:14-17.
21. Berkowitz RJ, Turner J, Green P. Maternal salivary levels of Streptococcus mutans and primary oral infection of infants. Arch Oral Biol 1981;26:147-149.

22. Thorild I, Lindau-Jonson B, Twetman S. Prevalence of Streptococcus mutans in mothers and in their preschool children. Int J Ped Dent 2002;12(1):2-7.

23. Li Y, Wang W, Caufield PW. The fidelity of mutans streptococci transmission and caries status correlates with breast feeding experience among Chinese families. Caries Res 2000;34: 123-132.

24. Emanuelsson IR, Thornqvist E. Distribution of mutans streptococci in families: a longitudinal study. Acta Odontol Scand 2001;59(2):93-98.

25. Saarela M, et al. Transmission of oral bacterial species between spouses. Oral Microbiol Immunol 1993;8:349-354.

\section{ABOUT THE AUTHORS}

\section{Amar N Katre (Corresponding Author)}

Associate Professor, Department of Pediatric Dentistry, YMT Dental College and Hospital, Kharghar, Navi Mumbai, Maharashtra, India

\section{SG Damle}

Vice Chancellor, Maharishi Markandeshwar University, Mullana Ambala, Haryana, India 